\title{
PENGEMBANGAN LEMBAR KERJA PESERTA DIDIK BERDASARKAN IDENTIFIKASI TANAMAN OBAT MASYARAKAT SERAWAI DESA KARANG ENDAH KEPAHIANG
}

\author{
Indah Pertiwi ${ }^{1 *}$, Ariefa Primair Yani ${ }^{1}$, Irwandi Ansori ${ }^{1}$ \\ ${ }^{1}$ Program Studi Pendidikan Biologi, Fakultas Keguruan dan Ilmu Pendidikan, Universitas Bengkulu \\ Email: pertiwiindah228@gmail.com
}

\begin{abstract}
Abstrak
Penelitian ini bertujuan untuk mengetahui jenis tanaman obat di perkarangan yang digunakan masyarakat Serawai di desa Karang Endah, mengetahui bagian tumbuhan yang digunakan dan untuk melihat kelayakan LKPD yang telah dikembangkan berdasarkan uji validator logis (guru dan dosen) dan empiris (peserta didik) kelas XIPA SMAN 01 Kepahiang materi keanekaragaman hayati sub bab manfaat keanekaragaman hayati sebagi bahan obat. Jenis penelitian ini adalah penelitian dan pengembangan (R\&D) dengan langkah utama Borg and Gall yang telah dimodifikasi yaitu potensi dan masalah, pengumpulan data, desain produk LKPD, validasi desain, revisi desain dan validasi empiris. Instrumen yang digunakan yaitu lembar observasi lapangan, lembar wawancara, lembar angket validasi logis. Berdasarkan penelitian didapatkan 63 jenis tanaman obat yang terbagi menjadi 34 famili tanaman. Penggunaan LKPD dalam pembelajaran dikatakan "layak" dengan hasil validasi logis mendapat nilai ratarata 91,1 \% dengan krriteria "sangat valid" dan hasil uji validasi empiris mendapatkan rata-rata nilai $85 \%$ (sangat baik) dengan ketuntasan klasikal 100\%. Dapat disimpulkan bahwa LKPD manfaat keanekaragaman hayati sebagai obat Layak digunakan dalam pembelajaran.
\end{abstract}

Kata kunci: LKPD, Tanaman Obat, Validator Empiris

\begin{abstract}
This study aims to determine the types of medicinal plants used the yard by Serawai people in Desa Karang Endah village, to know the part of the plant used, and to see the feasibility LKPD that was developed from validator logis (teacher and lecturer) and Empires (pupil) X IPA SMAN Number One of Kepahiang. The sub-bab in this research is the kind and type of Hayati as medical chemists. The kind of this research is research and development $(R \& D)$ with the major step Borg and Gall that was modified is potential and problem, data collection, and product design LKPD, design validation, design revision, validator empires. Instruments that used in this research are observation form, interview form, and also paper of validation logic. Base of this research we got 63 type of medical plant that divided into 34 Family plants. Using of LKPD in this learning was said "good enough" with validation result logic that got average score $91,1 \%$ with criteria "good validation" and result of test classic survival skill Empires got average score $85 \%$ "very Good" with classic survival skill Empires 100\%. It can conclude that LKPD is very useful in variety of Hayati as good medical in Learning.
\end{abstract}

Kata kunci: LKPD, Medical Plant, Emperies Validator

\section{PENDAHULUAN}

Biologi merupakan bagian dari ilmu pengetahuan alam yang lahir dan berkembang berdasarkan observasi dan eksperimen. Pada pembelajaran biologi, lingkungan alam sekitar merupakan laboratorium yang memiliki peranan penting karena banyak memberikan informasi bagi kehidupan manusia, dimana pembelajaran biologi harus memuat pengetahuan dan sikap positif tentang potensi lokal setempat 
sehingga dapat memotivasi peserta didik untuk belajar dan mengembangkan keterampilan sesuai potensi lokal yang ada disekitar, biologi juga berperan dalam mengembangkan potensi sumber daya lokal dan memberikan pembelajaran tentang bagaimana pemanfaatan dan pelestariannya (Sundari, 2018).

Rustaman (2010) Menyatakan bahwa penelitian pendidikan biologi tidak hanya terbatas pada penelitian berbasis kelas, namun masih banyak aspek lain yang dapat diangkat sebagai penelitian pendidikan biologi seperti kearifan lokal dalam kelompok-kelompok budaya tertentu dari generasi ke generasi berikutnya dan dihubungkan dengan pemanfaatannya oleh kelompok budaya tersebut yang nanti akan dijadikan sumber belajar biologi di SMA.

Menurut Prastowo (2011) Sumber belajar merupakan segala sesuatu yang bisa berupa benda, data, fakta, atau sesuatu yang terdapat di lingkungan kegiatan belajar yang dapat dipergunakan secara fungsional agar terwujudnya suatu pembelajaran yang dapat menunjang pendidikan. Lingkungan berkaitan dengan kegiatan pembelajaran, dimana jenis-jenis tumbuhan obat juga bermanfaat didalam dunia pendidikan khususnya didalam pembelajaran biologi

Tanaman obat adalah tanaman yang bagiannya organnya digunakan sebagai obat, baik yang sengaja ditanam maupun tumbuh secara liar (Herbie, 2015). Bagian tanaman yang digunakan sebagai bahan obat tradisional akan yang diekstraksi, dan ekstrak tanaman tersebut digunakan sebagai obat (Siswanto, 1997). Penggunaan tanaman dalam penyembuhan adalah bentuk pengobatan tertua di dunia, WHO (World health Organization) pada tahun 1985 memperediksi bahwa sekitar $80 \%$ penduduk dunia telah menggunkan tumbuhan obat
(Herbal medicine, phytotherapy, phytomidicine atau botanical medicine) untuk memelihara kesehatannya (Murni, 2012 dalam dorly 2005).

Pengobatan secara tradisional ini sudah lazim dan banyak digunakan masyarakat setempat dengan etnik masyarakatnya tersendiri: Enggano, Kaur, Lembak, Mukomuko, Pekal, Rejang, Pasemah, Suban dan masyarakat Serawai. Masyarakat Serawai yang lazim disebut orang Serawai ini berada diwilayah Bengkulu bagian Selatan dan menyebar ke bagian lainnya termasuk ke bagian Kepahiang. Masyarakat Serawai ini masih sangat sering mempergunakan obatobat tradisional dalam pengobatan, pengetahuan ini mereka dapatkan secara turun-temurun (Adfa, 2005).

Mayoritas masyarakat Desa Karang Endah masih memanfaatkan tanaman sebagai obat dalam pengobatan. Pemanfaatan tanaman obat di desa ini masih belum terlaksana secara menyeluruh dikarenakan pengetahuan tentang manfaat tanaman masih didapatkan dari lisan ke lisan. Pengetahuan mengenai tanaman obat di desa ini hanya dilakukan secara turun temurun dari generasi ke generasi (keturunannya). Hasil observasi di SMAN 01 Kepahiang diperoleh informasi bahwa Lembar Kegiatan Peserta Didik (LKPD) sebagai pendukung pembelajaran masih menggunkan LKPD penerbit yang belum memanfaatkan potensi lokal sebagai dumber belajar.

Berdasarkan hal tersebut, maka peneliti melakukan penelitian tentang Pengembangan LKPD berdasarkan tanaman obat suku Serawai desa Karang Endah pada materi keanekaragaman hayati kelas $X_{i p a}$ SMAN 01 Kepahiang yang nantinya diharapkan hasil penelitian ini akan memberikan informasi terhadap masyarakat 
luas tentang pengetahuan mengenai tumbuhan apa saja yang dimanfaatkan, sehingga adanya dokumentasi atau catatan tentang pengetahuan tentang tanaman obat-obatan oleh masyarakat Serawai khususnya di desa Karang Endah Kabupaten Kepahiang.

Studi tanaman obat ini juga dijadikan sebagai salah satu bahan sumber belajar biologi SMA dalam bentuk LPKD pada materi keanekaragaman hayati dengan Kompetensi Dasar (KD): 3.2 Menganalisis data hasil obervasi tentang berbagai tingkat keanekaragaman hayati (gen, jenis dan ekosistem) di Indonesia, dengan sub bab Manfaat Keanekaragaman Hayati Sebagai Sumber Obat.

\section{METODE}

Jenis penelitian yang dilakukan adalah penelitian dan pengembangan. Prosedur penelitian yang dilakukan mengadaptasidari Sugiyono (2009) yang memiliki 10 tahapan yaitu: (1) potensi dan masalah; pengumpulan data; (3) desain produk; (4) validasi desain; (5) uji coba pemakaian produk; (6) revisi desain; (7) uji coba produk; (8) uji coba produk; (9) revisi desain; (10) produksi massal, namun peneliti hanya menggunakan 6 tahapan yang telah dimodifikasi yaitu: (1) potensi dan masalah; (2) pengumpulan data; (3) desain Produk; (4) validasi desain atau validasi logis dengan meminta kepada para validator untuk menilai LKPD sebelum diuji cobakan kepada siswa, adapun validasi logis ini dilakukan oleh satu dosen pendidikan biologi sebagai ahli media dan 2 orang guru mata pelajaran biologi kelas X SMA dengan cara menilai LKPD melalui angket yang telah disiapkan peneliti ; (5) revesi desain (yaitu revisi dari hasil validasi logis) dan (6) validasi empiris (yaitu validasi yang dilakukan kepada 20 orang siswa kelas X SMA dengan melakukan uji coba LKPD dalam proses pembelajaran.

Penelitian ini telah dilaksanakan pada Bulan April 2019 di SMA Negeri 01 Kepahiang. Subjek penelitian ini adalah peserta didik kelas $X_{\text {IPA5 }}$ yang berjumlah 32 orang. Objek penelitian ini adalah LKPD. Variabel penelitian ini adalah LKPD hasil pengembangan dari studi keanekaragaman jenis tanaman obat Desa Karang Endah. Pada langkah kedua yaitu teknik pengumpulan data, teknik pengumpulan data dalam penelitian ini adalah wawancara terhadap masyarakat desa Serawai di Karang Endah, angket penilaian dari validator logis dan tes atau penilaian validator empiris.

Teknik analisis data pada penelitian ini yang pertama yaitu analisis validasi logis LKPD. Data hasil validasi logis LKPD yang diperoleh dari masing-masing validator didapatkan dengan menggunakan skala likert. Skor dari masing-masing aspek akan dihitung menggunakan rumus berikut:

$\frac{\text { Jumlah Skor Lembar Validasi }}{\text { Skor Maksimal }} \times 100 \%$ (Riduwan, 2013).

Hasil persentase dari masing-masing validator akan dihitung rata-ratanya per aspek penilaian, setelah itu akan dihitung per masing-masing validator, kemudian disesuaikan dengan kategori penilaian pada Tabel 1 Seperti dibawah ini:

Tabel 1. Kategori Penilaian Kevalidan LKPD

\begin{tabular}{cc}
\hline Presentase & Kategori \\
\hline $81 \%-100 \%$ & Sangat valid \\
$61 \%-80 \%$ & Valid \\
$41 \%-60 \%$ & Cukup Valid \\
$21 \%-40 \%$ & Kurang Valid \\
$0 \%-20 \%$ & Tidak Valid \\
\hline
\end{tabular}

(Riduwan, 2013).

Teknik analisis data kedua yaitu validasi empiris LKPD. LKPD yang telah 
dikerjakan oleh peserta didik dinilai berdasarkan rata-rata indikator. Nilai tersebut dirata-ratakan kemudian disesuaikan dengan kategori penilaian pada Tabel 2 berikut ini:

Tabel 2. Kategori Penilaian LKPD

\begin{tabular}{cc}
\hline Presentase & Kategori \\
\hline $81-100$ & Sangat Baik \\
$61-80$ & Baik \\
$41-60$ & Cukup Baik \\
$21-40$ & Kurang Baik \\
$0-20$ & Tidak Baik \\
\hline & (Riduwan, 2013).
\end{tabular}

Jika nilai rata-rata dari keseluruhan validator mendapatkan nilai minimal mencapai 61 atau lebih, maka produk pengembangan LKPD dinyatakan layak untuk digunakan didalam pembelajaran.

\section{HASIL DAN PEMBAHASAN}

Studi tanaman obat di Desa Karang Endah mendapatkan sampel tanaman obat sebanyak 63 jenis tanaman yang terbagi kedalam 34 famili tanaman. Tanaman yang paling banyak digunakan merupakan tanaman dari famili Zingiberaceae. Studi tanaman obat ini pernah diteliti sebelumnya oleh Melda (2018) di Seluma yang mendapatkan 88 jenis tanaman yang terbagi kedalam 44 famili dan penelitian Listari (2007) di Manna Bengkulu Selatan yang mendapatkan 65 jenis tanaman yang terbagi kedalam 38 famili tanaman. Studi keanekaragaman tanaman di Desa Karang Endah ini akan menjadi bahan di dalam pembuatan LKPD Tentang manfaat keanekaragaman hayati sebagai bahan obat. LKPD dibuat dengan cara menganalisis kurikulum SMA, yaitu menentukan KD yang telah disesuaikan yakni KD keanekaragaman Hayati tentang pemanfaatan tanamansebagai obat. Selanjutnya LKPD didesain dengan menentukan indikator dan tujuan pembelajaran yang harus dicapai oleh peserta didik. Penyusunan LKPD juga mengikuti panduan penyusunan menurut para ahli(Widjajanti, 2008; Depdiknas, 2008) dengan Penyusunan LKPD yakni: judul, kompetensi yang akan dicapai, konsep, informasi pendukung, alat dan bahan, langkah-langkah kerja dan soal diskusi serta disertai lembar saran untuk melihat saran perbaikan LKPD pengembangan dari peserta didik.

LKPD pengembangan yang di validasi oleh 3 orang validator yaitu 1 orang dosen Pendidikan Biologi dan 2 orang guru mata pelajaran Biologi SMA dapat dilihat hasilnya pada Tabel 3 dibawah ini.

Tabel 3. Presentase Aspek Penilaian Validator

\begin{tabular}{llll}
\hline No & \multicolumn{1}{c}{ Aspek } & Presentase & Katagori \\
\hline 1 & Materi & $96 \%$ & Sangat valid \\
2 & Kebahasaan & $83 \%$ & Sangat valid \\
3 & Penggunaan & $89 \%$ & Sangat valid \\
4 & Kegrafisan & $89 \%$ & Sangat valid \\
\hline
\end{tabular}

Presentase validasi logis sebelum dimasukkan ke Tabel katagori kevalidan LKPD akan dinilai berdasarkan rata-rata setiap penilaian validator. Adapun rata-rata setiap validator dapat dilihat pada Tabel 4 dibawah ini:

Tabel 4. Persentase Validasi Logis LKPD

\begin{tabular}{llcc}
\hline No & \multicolumn{1}{c}{ Validator } & Persentase & Kategori \\
\hline 1. & $\begin{array}{l}\text { Dosen Pendidikan } \\
\text { biologi (AYZ) }\end{array}$ & $86,7 \%$ & $\begin{array}{c}\text { Sangat } \\
\text { Valid }\end{array}$ \\
2. & Guru Biologi 1 (SPS) & $94,1 \%$ & $\begin{array}{c}\text { Sangat } \\
\text { Valid }\end{array}$ \\
3. & Guru biologi & $92,6 \%$ & $\begin{array}{c}\text { Sangat } \\
\text { 2(DMN) }\end{array}$ \\
& & Valid \\
\hline Rata-rata 91,1\% (Sangat Valid)
\end{tabular}

Meskipun LKPD mendapatkan nilai dengan rata-rata sangat baik yaitu sebesar 91,1\% dengan kriteria (Sangat Valid), namun LKPD yang telah divalidasi logis oleh ketiga 
validator mendapatkan berbagai perbaikan agar LKPD layak untuk dihgunakan kepada peserta didik. Adapun saran dan perbaikan LKPD dapat dilihat pada table dibawah ini

Table 5. Saran dan Perbaikan LKPD oleh Validator

\begin{tabular}{llll}
\hline NO & \multicolumn{2}{c}{ Validator } & \multicolumn{1}{c}{ Perbaikan / saran terhadap LKPD } \\
\hline 1 & $\begin{array}{l}\text { Validator } \\
\text { biologi) }\end{array}$ & (Dosen pendidikan & $\begin{array}{l}\text { Sebaiknya pada LKPD tidak menggunakan emoticon / gambar yang } \\
\text { tidak berhubungan dengan LKPD dan perbaikan beberapa kalimat. }\end{array}$ \\
2 & Validator 2 (Guru Biologi) & $\begin{array}{l}\text { Sebaiknya tambahkan tujuan dan indikator yang akan dicapai siswa } \\
\text { pada LKPD, agar Ikpd lebih jelas dan siswa mudah memahami } \\
\text { indikator apa saja yang harus dicapai setelah mengguanakan LKPD. } \\
\text { Sebaiknya pelaksanaan uji pengembagan LKPD dilaksanakan sesuai } \\
\text { dengan jadwal kurikulum k13 }\end{array}$ \\
\hline
\end{tabular}

Tabel 6. Perbandingan LKPD Sebelum Dan Sesudah Direvisi

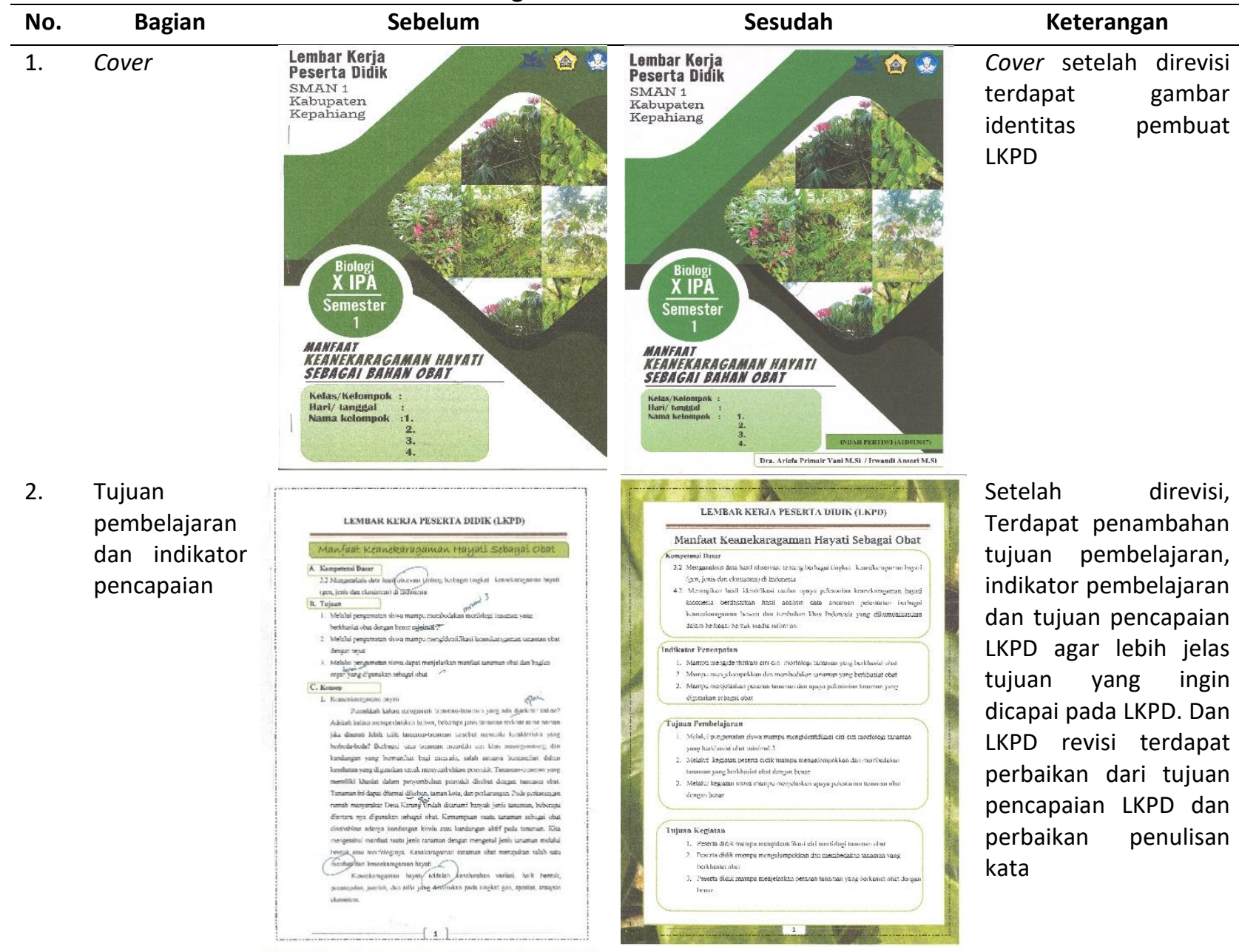


3. Gambar pada LKPD, dan latar belakang LKPD

4. Font, huruf dan Bahasa serta penambahan keterangan gambar penggunaan
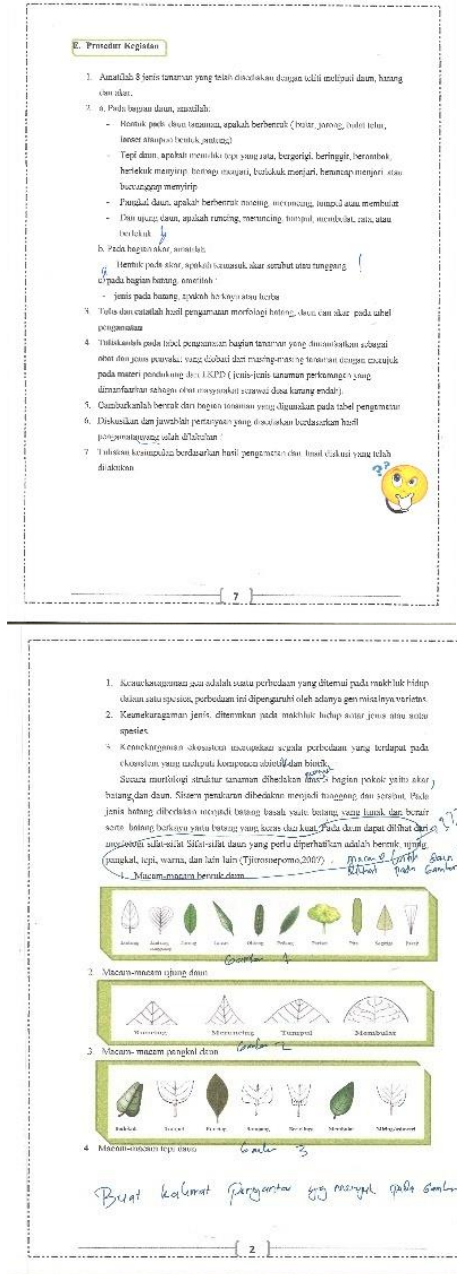

5. Penulisan kata depan untuk keterangan tempat

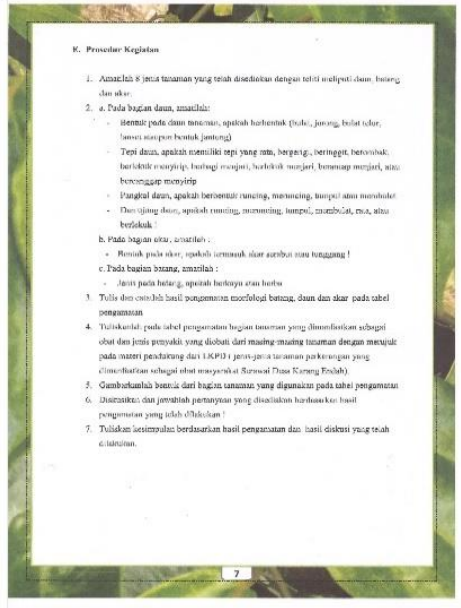

Gambar emoticon yang tidak jelas dan tidak berhubungan dengan LKPD dibuang agar tidak mengganggu konsentrasi dan proses peserta didik. Dan penambahan latar belakang untuk memotivasi peserta didik.

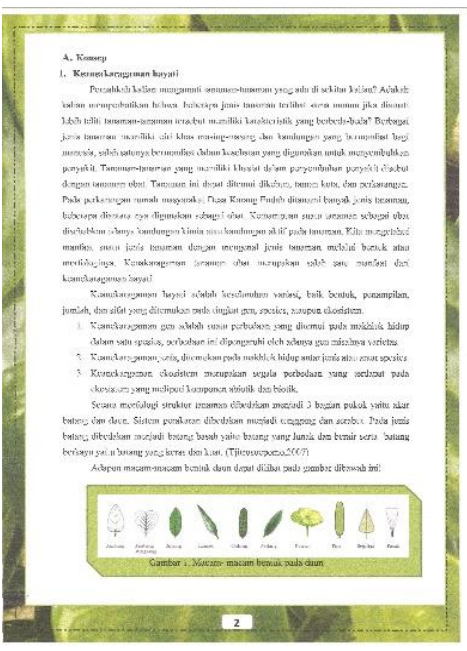

Setelah direvisi, LKPD diperbaiki dalam penulisan kata, gambar pada LKPD ditambahkan keterangan gambar dan Bahasa LKPD yang salah diperbaiki

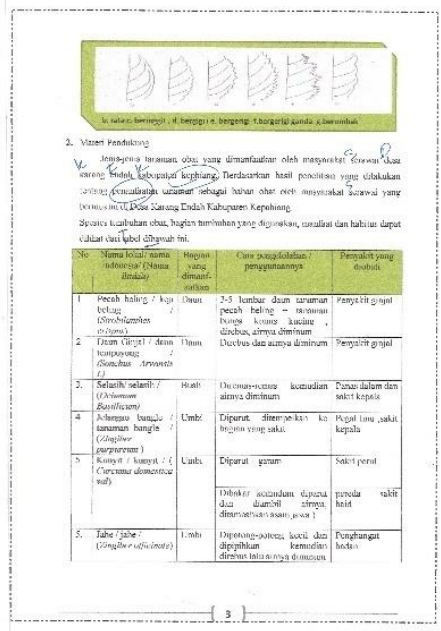

Setelah direvisi, LKPD diperbaiki dalam penulisan huruf pada LKPD dimana untuk keterangan tempat menggunakan huruf kapital diawal kalimat. 
Setelah direvisi, disusunlah desain akhir LKPD untuk divalidasi empiris oleh peserta didik. Uji validasi empiris ini dilakukan pada peserta didik kelas XIPA5 SMA negeri 01 Kepahiang yang berjumlah 7 kelompok dengan 4 peserta didik perkelompok. Uji validasi empiris ini dilakukan untuk menilaiLKPD yang dikerjakan oleh peserta didik berdasarkan rata-rata nilai perlevel indikator pencapaian LKPD. Hasil penilaian ketuntasan LKPD dapat dilihat pada Tabel dibawah ini.

Tabel 7. Hasil Penilaian LKPD Perlevel Indikator Yang Dikerjakan Peserta Didik

\begin{tabular}{llcc}
\hline No & \multicolumn{1}{c}{ Indikator } & $\begin{array}{c}\text { Rata- } \\
\text { rata }\end{array}$ & Kriteria \\
& & $80 \%$ & Baik \\
2 & Mengidentifikasi & $82 \%$ & Sangat Baik \\
3 & Mampu membedakan & $90 \%$ & Sangat Baik \\
& Mengelompokkan & & \\
4 & Mampu Menyimpulkan & $89 \%$ & Sangat Baik \\
\hline \multicolumn{2}{l}{ Rata - rata: 85\% (Sangat Baik) } \\
\hline
\end{tabular}

Setelah dilakukan validasi logis, LKPD diuji cobakan dalam skala kecil menggunakan validasi empiris. Menurut Sudaryono (2012) Uji coba validasi empiris diartikan sebagai validitas yang bersumber atas dasar pengamatan, dimana kriteria suatu tes atau instrumen dinilai dari hasil ukur instrumen yang bersangkutan. Menurut Uno dan Muhammad (2014) Penggunaan lingkungan sebagi sumber belajar memiliki beberapa kelebihan antara lain peserta didik dibawa langsung ke dalam dunia yang konkret tentang konsep pembelajaran, sehingga peserta didik tidak hanya mengkhayalkan materi. Pendapat ini juga didukung oleh Zukmadini, dkk (2018) yang menyatakan bahwa pengembangan bahan ajar berbasis kearifan lokal dalam penggunaan tanaman obat, memiliki potensi untuk membantu para guru dalam mencapai tujuan pembelajaran sesuai dengan tuntutan kurikulum dan standar kompetensi.

Berdasarkan hasil rata-rata indikator yang didapatkan mendapatkan nilai $85 \%$ dengan kriteria (sangat baik). Level yang tertinggi terletak pada level indikator membedakan yaitu presentase sebesar $90 \%$ dengan kriteria sangat baik, tingginya indikator tersebut karena unsur yang terkandung dalam LKPD memuat materi yang berhubungan dengan LKPD dan dikarenakan pada LKPD terdapat materi pendukung yang membantu peserta didik menjawab pertanyaan LKPD.

Level Kedua yang tertinggi terletak pada level menyimpulkan yaitu dengan presentase $89 \%$ dengan kriteria sangat baik, hal ini dikarenakan tabel pada bahan diskusi yang disusun cukup menggiring peserta didik menyimpukan, selain itu juga tingkat pemahaman peserta SMA sudah mampu menganalisis soal didalam LKPD. Hal ini sesuai dengan pendapat Purwanto (2011) Pemahaman jenjang kemampuan berfikir peserta didik usia 15-17 tahun memiliki tingkat pemahaman yang lebih tinggi dibandingkan anak usia 12-14 tahun yang hanya mampu menghafal dan mengingat.

Level terendah terdapat pada level mengidentifikasi yaitu sebesar $80 \%$ dengan kriteria baik, meskipun kriteria baik namun pada level ini pertanyaan pada LKPD terlalu tinggi dan sulit dikarenakan pertanyaan pada LKPD menuntut peserta didik untuk menganalisis dan menggunakan argumennya sehingga peserta didik cenderung mendapatkan nilai yang rendah.

Berdasarkan level yang telah ada LKPD ini mampu mengembangkan pemahaman konsep belajar peserta didik. Adapun keunggulan lainnya yaitu: (1) Desain LKPD yang menarik dan memotivasi 
peserta didik ; (2) LKPD memuat informasi dan materi konsep yang memanfaatkan lingkungan sekitar sehingga peserta didik lebih aktif dan termotivasi; (3) Pertanyaanpertanyaan LKPD mengarahkan peserta didik untuk memahami konsep keanekaragaman hayati dan materi dan tugas pada LKPD menunjang pencapaian tujuan kegiatan. Hal ini sesuai dengan Prastowo (2011) LKPD yang baik adalah LKPD yang membantu peserta didik menemukan konsep yang meliputi: mengamati, menggolongkan dan menarik kesimpulan.

\section{PENUTUP}

\section{Simpulan}

Berdasarkan hasil validasi logis dan empiris terhadap LKPD pengembangan, maka LKPD hasil pengembangan berdasarkan hasil studi keanekaragaman tanaman obat Desa Karang Endah Kabupaten Kepahiang dinyatakan layak untuk dijadikan bahan ajar dalam pembelajarandengan persentase 91\% oleh validator dan mendapatkan nilai rata-rata perindikator pemahaman senilai $85 \%$ oleh peserta didik.

Saran

Sebaiknya ada penelitian lebih lanjut untuk menguji keefektifitasan LKPD hasil pengembangan berdasakan studi keanekaragaman tanaman obat di daerah Kepahiang dan sebaiknya dilakukan uji coba secara individu untuk melihat keefektifitasan produk.

\section{DAFTAR PUSTAKA}

Adfa, M. 2005. Survey Etnobotani, Studi Senyawa Flavonoid Dan Uji Brine Shrimp Beberapa Tumbuhan Obat Tradisional Suku Serawai Di Propinsi
Bengkulu. Jurnal Gradien, 1(1), 43-50, diakses tanggal 23 september 2018.

Depdiknas.

2008.

Panduan

Pengembangan Bahan Ajar. Jakarta: Direktorat Pembinaan Sekolah Menengah Atas.

Dorly. 2005.Potensi Tumbuhan Obat Indonesia Dalam Pengembangan Industry Argonomi.Bogor:ITB .

Herbie, Tandi. 2015. Kitab Tanaman Berkhasiat Obat-226 Tumbuhan Obat untuk Penyembuhan Penyakit dan Kebugaran Tubuh. Yogyakarta: Octopus Publishing House.

Listari, N. 2007. Keanekaragaman Tumbuhan Obat Masyarakat Serawai Kecamatan Manna Bengkulu Selatan Dan Berdasarkan Naskah-Naskah Pengohahan Tradisional Serawai. Skripsi Tidak Diterbitkan. Program Pendidikan Biologi, Fakultas Keguruan Dan Ilmu Pendidikan: Universitas Bengkulu.

Melda. 2018. Studi Etnobotani Tumbuhan Obat Suku Serawai Sebagai Pengembanagan Handout Biologi Kelas X SMA. Diklabio:Jurnal Pendidikan dan Pembelajaran Biologi. 2(2):3738.

(Online).https://ejournal.unib.ac.id/ind ex.php/jppb/article/view/6802, Diakses tanggal 12 febuari 2019.

Uno, H.B., N. Mohamad, 2014. Belajar dengan Pendekatan PAILKEM. Jakarta: Bumi Aksara.

Prastowo, A. 2011. Panduan Kreatif Membuat Bahan Ajar Inovatif. Jogjakarta: Diva Press.

Purwanto. 2011. Evaluasi Belajar. Yogyakarta: Pustaka Pelajar. 
Siswanto. 1997. Sayuran Dataran Tinggi. Jakarta: Penebar Swadaya.

Sudaryono. 2012. Dasar-dasar Evaluasi Pembelajaran. Yogyakarta: Grana ilmu.

Sundari, R. 2008. Evaluasi Pemanfaatan Laboratorium dalam Pembelajaran Biologi di Madrasah Aliyah Negeri Sekabupaten Sleman. Jurnal Penelitian Dan Evaluasi Pendidikan, vol (2),196212.

https://doi.org/10.21831/PEP.V12I2.14 7,Diakses 12 oktober 2019.

Sugyono, 2010. Metode Penelitian Pendekatan Kuantitatif Kualitatif dan $R \& D$. Bandung: Alfabeta.

Riduwan. 2013. Skala Pengukuran VariabelVariabel Penelitian. Bandung: Alfabeta.

Rustaman, N.Y. 2010. Strategi Belajar Mengajar Biologi. Malang: UM Press.

Widjajanti, Endang. 2013. Kualitas Lembar Kerja Peserta didik. Jurusan Pendidikan Kimia Fakultas Matematika dan IImu Pengetahuan Alam Universitas Yogyakarta.

Zukmadini, Alif Yanuar., Dewi Jumiarni., Kasrina. 2018. Developing Antimicrobial Medicinal Plants Pocketbook Based On Local Wisdom Of Muko-Muko And Serawai Ethnics. Jurnal Pendidikan Biologi Indonesia. 4(2): 95-104. (Online) (http://ejournal.umm.ac.id/index.php Lipbi/article/view/5436/5518), Diakses pada 15 Juli 2019. 